\title{
LGBT testimony and the limits of trust
}

Trust and its limits within LGBT Healthcare

Journal of Medical Ethics-forthcoming

Maura Priest

Mpriest2@asu.edu

Arizona State University

*This is a Pre-publication DRAT*

\section{Introduction}

Notini et al.'s article makes a strong case for OPS's permissibility, and their conclusion will not be disputed here. Instead, I directly focus on issues that their article addressed only indirectly. This article will utilize a hypothetical case study to show that while Notini et al.'s ethical conclusion might be spot on, that perhaps the method they took to get there was superfluous.

Historically speaking, medical experts have dismissed, downplayed, and doubted, LGBT testimony, all of which manifests blatant disrespect. Related ethical failings include the once widely accepted assumption (among medical authorities) that LGBT identities were illnesses best treated and cured.[1 - 3$]^{\mathrm{i}}$ While conditions have improved over time, even today, LGBT patients have empirically warranted fears about medical discrimination.[4-9] ${ }^{\text {ii }}$ Physicians who will trust queer testimony and who will respect queer subjective aims is a first step away from the ethically troubled past and present. However, Notini et al.'s article motivates a worry: will medical experts have an implicit "contentclause" regarding their trust in LGBT testimony? Will this testimony be trusted and respected only if deemed "reasonable"?

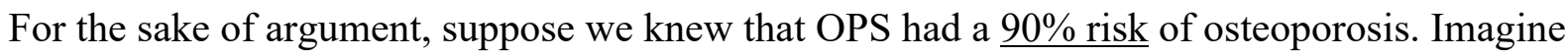
that a non-binary patient, 'Chicago,' who fully understands the physical risks, still insists that OPS is necessary for their wellness. Does the osteopetrosis risk justify rejecting Chicago's request for OPS? Regardless, it seems inconsistent to approve OPS for Phoenix but disapprove OPS for Chicago. The difference between these patients is one of degree, not of kind (greater risk for Chicago.) Increased risk itself is not enough to justify disparate treatment. Risk must be weighed against reward, and enough of the latter can overcome the former. What, then, might motivate reflective assumptions that OPS is okay 
for Phoenix but unjustified for Chicago? Divergent recommendations might be explained by either, (1) prioritizing physical over psychological health, e.g., in assuming that osteopetrosis is worse than gender dysphoria, or (2), skepticism toward Chicago's testimony. Both (1) and (2) are ethically dubious.

Psychological illness, like physical illness, might be life-threating. [10-13] ${ }^{\text {iii }}$ So prioritizing physical over psychological health cannot be grounded in the former's severity or permanence. Moreover, there is no logical nor empirical evidence suggests that physical suffering must be worse than psychological suffering. Blanket prioritizations of physical over psychological health are conceptually and scientifically unfounded.

Medicine's ethically insecure history within the LGBT community justifies skepticism toward physicians' skepticism of LGBT testimony. This skepticism seems especially warranted in response to physicians who might be skeptical of Chicago. Chicago contends that OPS's identify-affirming benefits justifies the serious risk of osteoporosis. This preference might seem unusual, but we must remember that both values and experience can impact suffering. Judging norm deviant preferences as 'misguided' (without further reason) is not only epistemically suspect, it violates the patient's right to autonomy. Physician skepticism toward Chicago, if justified, must amount to much more than, "their choice seems strange and unreasonable." Norm-deviant preferences, behaviors, and values, should never be assumed unreasonable because of the deviation alone. Homosexual orientation and trans-identities also deviate from the norm. Medicine slowly accepted that this deviance is perfectly compatible with psychological wellness. Default skepticism toward those who prioritize identify-affirming care seems a big step backward. It is returning to a world where unusual preferences and assumed psychological illness go hand-in-hand.

Hypothesized Chicago motivates this question: was Notini et al.'s careful cost/benefit calculation regarding OPS superfluous? Arguably, yes. OPS for non-binary patients seems warranted provided that, (1) patients understand the treatment and risks, and, (2) patients testimony that the benefits outweigh the costs. Patients, not physicians, have something to both lose and gain. Moreover, only patients have direct access to the subjective upsides. Notini et al. do acknowledge that, "Many of the potential harms we identified seemed largely dependent on Phoenix's values..." The authors acknowledge that subjective value is a critical factor in assessing harm. But then why not take competent patients at their word? Medical risks must be weighed against (largely psychological) benefits, yes. Physicians are well situated to educate patients about the former. Only patients have direct access to the latter. Thus, a clash between a patient's and a physician's cost/benefit analysis in itself implies that the latter understands the 
patient better than the patient does themselves. Given medicine's history with LGBT patients, this is not only implausible, but arrogant and ethically suspect.

Heteronormativity has long fueled LGBT medical mistreatment. To avoid going back down that path, medicine must leave room for diverse and atypical health prioritizations. Even if OPS was far riskier than recognized, it might remain the best path for some non-binary patients (those for whom identity affirmation warrants even serious physical risk.)

Notini et al.'s discussion opens the door to a related ethical challenge. Thanks to guardian consent, as a youth Phoenix had received pediatric PS making O(ongoing)PS possible. However, some guardians of non-binary patients withhold this consent, and then androgynous puberty is inevitable. Because completed processes can no longer be suppressed; without pediatric PS, OPS is off the table. The aligning of the parental stars can thus determine whether adulthood begins with either, (1) a confidence inducing, gender affirming body, or, (2) a confidence-undermining body that intensifies gender dysphoria.

Two non-binary teens desiring comparable treatments are like cases, hence justice demands like treatment. Guardian veto power over identify-affirming care thus result in injustice whenever such power means one trans child is denied the care that another receives. This veto power also conflicts with the principles of non-maleficence, autonomy, and beneficence. Autonomy is infringed because medical options are forever closed off to those who (through no choice nor fault) miss PS in adolescence. Frustrating a trans person's desire to affirm identity is harmful, i.e., in tension with non-maleficence. Lastly, parental veto-power over PS forever keeps many identity-affirming benefits out of reach, thus failing compliance with beneficence. 


\section{References}

1. Drescher J. A history of homosexuality and organized psychoanalysis. Journal of the American Academy of Psychoanalysis and Dynamic Psychiatry 2008;36(3):443-460.

2. De Block A, Adriaens, PR. Pathologizing sexual deviance: A history. Journal of sex research 2013;50(3-4):276-298;32.

3. Herek GM. Sexual orientation differences as deficits: Science and stigma in the history of American psychology. Perspectives on Psychological Science 2010;5(6):693-699.

4. Lim FA, Brown Jr DV, Kim SMJ. CE: Addressing health care disparities in the lesbian, gay, bisexual, and transgender population: A review of best practices. AJN The American Journal of Nursing 2014;114(6):24-34.

5. Sabin JA, Riskind RG, Nosek BA. Health care providers' implicit and explicit attitudes toward lesbian women and gay men. American Journal of Public Health 2015;105(9):1831-1841.

6. Bonvicini KA. LGBT healthcare disparities: What progress have we made? Patient education and counseling 2017;100(12):2357-2361.

7. Foglia MB, Fredriksen-Goldsen KI. "Health disparities among LGBT older adults and the role of nonconscious bias." Hastings Center Report 44 2014;s4:S40-S44.

8. McClain Z, Hawkins LA, Yehia BR. Creating welcoming spaces for lesbian, gay, bisexual, and transgender (LGBT) patients: An evaluation of the health care environment. Journal of homosexuality 2016;63(3):387-393.

9. Banerjee SC, Walters CB, Staley JM, et al. Knowledge, beliefs, and communication behavior of oncology health-care providers (HCPs) regarding lesbian, gay, bisexual, and transgender (LGBT) patient health care. Journal of health communication 2018;23(4):329-339.

10. Hawton K, i Comabella CC, Haw C, et al. Risk factors for suicide in individuals with depression: a systematic review. Journal of affective disorders 2013;147(1-3):17-28.

11. Bauer GR, Scheim AI, Pyne J, et al. Intervenable factors associated with suicide risk in transgender persons: A respondent driven sampling study in Ontario, Canada. BMC Public Health 2015;15(1):525. 12. Haas AP, Eliason M, Mays VM, et al. Suicide and suicide risk in lesbian, gay, bisexual, and transgender populations: Review and recommendations. Journal of Homosexuality 2011;58(1):10-51. doi:10.1080/00918369.2011.534038 [published Online First: 4 January 2011]. 13. Tannehill B. "The Truth About Transgender Suicide." The Huffington Post 2015 Nov. https://www.huffingtonpost.com/brynn-tannehill/the-truth-about-transg (accessed Day Mon Year) 
${ }^{\text {i }}$ See Drescher, 2008; De Block, \& Adriaens, 2013; and Herek, 2010.

ii See Lim et al., 2014; Sabin et al., 2015; Bonvicini, 2017; Foglia et al., 2014; McClain et al., 2016; and Banerjee, 2018.

iii A literature review on suicide and depression can be found in Hawton et al., 2013. For articles covering trans and/or LGBT depression and suicide see Bauer et al., 2015; Haas, 2010; Tannehill, 2016; and Steele et al., 2019. 